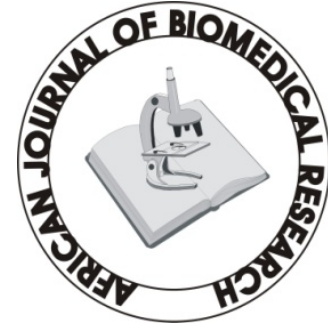

Full-text available at http://www.ajbrui.com http://www.bioline.br/md http://www.ajol.com

Received:

February 2008

Accepted (Revised): April 2008

Published

May 2008
Full Length Research Article

\section{The Mycobacterium tuberculosis homologue of the Mycobacterium avium mig gene is not specifically expressed in the macrophage}

\section{1,2 ,Terry Alli O .A. ${ }^{1,3}$ Hingley-Wilson S., ${ }^{2}$ Ogbolu D.O., and ${ }^{1}$ Spreadbury Claire L.}

${ }^{1}$ Molecular Mycobacteriology Research Group, Department of Infection, The Medical School, University of Birmingham, Birmingham, B15 2TT

${ }^{2}$ Department of Biomedical Sciences, College of Health Sciences, Ladoke Akintola University of Technology, Ogbomoso, Nigeria

${ }^{3}$ Department of Infectious Diseases, Imperial College, University of London, London

\section{ABSTRACT}

With the completion of genome sequencing of Mycobacterium tuberculosis and upsurge in the incidence of $M$. tuberculosis infection worldwide partly as a result of HIV pandemic, there is need for rationale approach to vaccine and chemotherapy discoveries for $M$. tuberculosis. The homologue of mig gene of Mycobacterium avium was searched for in the M. tuberculosis database at The Institute of Genomic Research (TIGR), USA and The Sanger Institute, UK. Homologue of the gene was found and comprehensively analysed. Reverse transcription PCR (RT-PCR) was carried out on the mig (fadD19) gene homologue and echA19 gene. The result of the RT-PCR showed that the mig gene was at least 2-fold upregulated during intracellular infection of macrophage compared to the broth grown bacilli as opposed to the demonstrated specific expression of mig gene in $M$. avium infected macrophage. The echA19 gene was also found to be upregulated. .

(Afr. J. Biomed. Res. 11: 173 - 181)

Key Words; macrophage induced gene, mig gene, Mycobacterium tuberculosis

*Corresponding Author: E-mail: alliot@hotmail.com; Phone: +234(0)805 6586849.

Abstracted by:

African Index Medicus (WHO), CAB Abstracts, Index Copernicus, Global Health Abstracts, Asian Science Index, Index Veterinarius, Bioline International , African Journals online 


\section{INTRODUCTION}

Mycobacterium tuberculosis is the leading cause of death from infectious diseases after human immunodeficiency virus (HIV) (Corbett and Raviglione, 2005). The resurgence of tuberculosis as a result of $M$. tuberculosis infection is due to the HIV pandemic and the emergence of multidrug resistant strains of $M$. tuberculosis, which make the treatment of tuberculosis very difficult. It has been estimated that the new cases of TB in 2005 to be around 8.8 million people (WHO, 2007). The global prevalence of $M$. tuberculosis infection was estimated to be $32 \%$, with $0.18 \%$ of the world's population dually infected with $M$. tuberculosis and HIV (Corbett and Raviglione, 2005). Two regions, Africa (Nigeria and South Africa being the highest burden countries in Africa) and the Asia, were mainly responsible for the upward trend in incidence rates (WHO, 2007).

In order to arrest this trend, there is need for rationale approach to research into chemotherapy and vaccine development for TB. How Mycobacterium tuberculosis survives and replicates within the hostile environment of the host macrophage is not understood. Genes specifically expressed by $M$. tuberculosis during intracellular infection may encode factors which enable the bacilli to resist the host's microbicidal defences and thus may be virulence determinants. The finding that Mycobacterium avium possess a gene (mig gene) which is specifically induced during infection of macrophages (Plum et al., 1997, Plum and Clark-Curtiss, 1994) raises the exciting possibility that a homologue of this gene may exist in $M$. tuberculosis which may also be specifically macrophage induced.

The study reported here was performed to investigate the presence of mig gene homologue in $M$. tuberculosis and to determine under what conditions the gene is actually being expressed.

\section{MATERIALS AND METHODS}

DNA Sequence analyses. Sequences of the mig gene from Mycobacterium avium (Plum et al., 1997) were used to screen the Mycobacterium tuberculosis DNA sequences database at The
Institute of Genetic Research (TIGR), USA, National Centre for Biotechnology Information, USA and Sanger Centre, Hinxton, Cambridge, UK for sequences homology using the blast program (Altschul et al., 1990).

Maintenance and cultures of mycobacteria and macrophage cell line. Mycobacterial species used in this study was M. tuberculosis H37Rv (ATCC 9360) obtained from the National Culture Type Collection, Colindale, UK. Mycobacteria were grown to mid log phase in Middlebrook 7H9 broth (Difco Laboratories Ltd., Surrey, UK) supplemented with $10 \%$ albumin-dextrose catalase enrichment (ADC; Difco) and 0.02\% Tween 80 (Sigma, Dorset, UK) at $37^{\circ} \mathrm{C}$ (in the presence of $5 \% \mathrm{CO}_{2}$ for $M$. tuberculosis) before harvesting at 0.5-1.0 $\mathrm{OD}_{600}$. M. tuberculosis $\mathrm{H} 37 \mathrm{Rv}$ cultures were also grown for 3 weeks at $37^{\circ} \mathrm{C}$ on thick $7 \mathrm{H} 10$ agar plates supplemented with $10 \%$ oleic acid-albumin-dextrose catalase enrichment (OADC; Difco) and $0.2 \%$ glycerol and then stored at $4^{\circ} \mathrm{C}$.

The murine macrophage cell line J774.2 (obtained from European Collection of Cell Cultures, CAMR, Porton Down, Salisbury, UK) was used in all infection experiments. J774.2 macrophages were cultured in Dulbecco's modified Eagle's medium (DMEM) containing $5 \%$ heat-inactivated foetal bovine serum (Life Technologies, Paisley, UK) with no antibiotic supplements. Macrophage monolayers were maintained at $37^{\circ} \mathrm{C}$ in humidified air containing $5 \% \mathrm{CO}_{2}$ before and after infection. For storage purposes, cell pellets were suspended in 9\% dimethyl sulphoxide (DMSO) in foetal bovine serum (FBS) at a concentration of approximately 4 $\times 10^{6}$ cells $/ \mathrm{ml}$ and aliquoted into $1 \mathrm{ml}$ cryo-vials (Nunc, UK). The vials were placed in a polysytrene box and then placed at $-20^{\circ} \mathrm{C}$ overnight before transferring to liquid nitrogen.

Macrophage infections and preparation of RNA. J774.2 macrophages were synchronisely infected overnight with non-opsonised static cultured of 10:1 M. tuberculosis bacilli in mid log phase (Schlesinger et al., 1990). After $4 \mathrm{hr}$, the medium was discarded and washed in three 
changes of Hanks' balanced salt solution to remove the extracellular bacilli before the infected cell line layer was resuspended in DMEM. A control comprised $M$. tuberculosis bacilli growing in Middlebrook 7H9/ADC/Tween 80 broth without shaking. RNA was prepared from macrophages infected with $M$. tuberculosis using a method based on a differential lysis after overnight incubation. Briefly, the culture medium was discarded and the infected macrophage monolayers were re-suspended in $25 \mathrm{ml}$ guanidine thiocyanate solution per flask to lyse the macrophages. In order to reduce the viscosity of the solution, a long thin nosed plastic Pasteur pipette was used to squirt the lysate solution in and out with force to shear the macrophage nucleic acids. The lysates were transferred to $30 \mathrm{ml}$ sterile universal tubes and centrifuged at 2,500×g for 20 min to concentrate the intracellular bacilli. The pellets of intracellular bacilli were combined using $1 \mathrm{ml}$ of wash solution ( $1 \mathrm{ml} 0.5 \%$ Tween 80$)$ and transferred to a $1.5 \mathrm{ml}$ Eppendorf tube and centrifuged in a microcentrifuge at $12,000 \times \mathrm{g}$ for 30 sec. The supernatant (wash solution) was saved and placed in a fresh Eppendorf tube and stored at $-80^{\circ} \mathrm{C}$. The pellet of bacteria was re-suspended in $200 \mu$ of sterile DEPC treated water. The RNA was extracted from the harvested intracellular bacilli and the extracellular bacilli control using Mangan et al's method (Mangan et al., 1997). All RNA samples were DNase I treated to destroy any contaminating DNA by incubating the RNA samples in the presence of DNase I (Pharmacia) for $30 \mathrm{~min}$.

RT-PCR for $16 S$ gene in M. tuberculosis. A competitive template was prepared as described by Celi et al. (Celi et al., 1993). The nucleotide sequence encoding the 16S rRNA gene accession no. X52927 (Kempsell et al., 1992) was analysed and primers were designed to amplify a fragment of $471 \mathrm{bp}$. The primers were designated 16SRibA (5'-CTGGCGGCGTGCTTAACACA-3') and 16SRibB (5'-ACGTAGTTGGCCGGTGCTTC-3') for the upstream and downstream primers, respectively. Fifty picograms of $M$. tuberculosis DNA was amplified in a reaction volume containing $0.125 \mathrm{mM}$ of dNTPs, $10 \mathrm{mM}$ Tris-HCl
(pH 8.3), $1.5 \mathrm{mM} \mathrm{MgCl}_{2}, 50 \mathrm{mM} \mathrm{KCl}, 0.01 \%$ gelatin, $1 \mu \mathrm{M}$ of each primer, and $0.5 \mathrm{U}$ of Taq I polymerase. The cycling parameters were $94^{\circ} \mathrm{C}(1$ min); $60^{\circ} \mathrm{C}(2 \mathrm{~min}) 72^{\circ} \mathrm{C}$ (3 min) for 25 cycles and $72^{\circ} \mathrm{C}$ (7 min) for 1 cycle. To generate a competitive template for the 16S rRNA gene, a third primer, 16SRibD, (5'ACGTAGTTGGGCGGTGCTTCGCTGCATCAG GCTTG-3') was designed from the nucleotide sequence 113 bases further inward from the 16SRibB primer sequence. The new primer comprised 15 bases attached to the 3' end of the entire 16SRibB primer to generate a primer of 35 bases in length. Primers 16SRibA and 16SRibD were used to amplify an expected product of 355

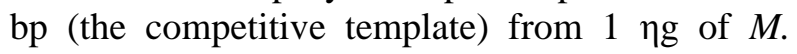
tuberculosis DNA using the same cycling parameters. The competitive PCR product was electrophoresed through a $1 \%$ agarose gel in TAE buffer. The DNA bands were excised and purified using the GeneClean kit. The competitive amplicon was re-amplified using primers 16SRibA and 16SRibB and electrophoresed through a 1\% agarose gel. The concentrations of the DNA of competitive amplicons were determined by spectrophotometry and by gel electrophoresis against a known concentration of DNA. A tenfold dilution series of the competitive amplicons were performed and amplified in a PCR to determine the lower limit of detection. This was necessary in order to determine the dilution range to be used in subsequent competitive PCR. Further experiments were also undertaken to determine if there was any interaction between the competitive and native amplicons during PCR to check for the formation of hybrids which could negate the results of the competitive PCR. The various dilutions of the competitive amplicon were stored at $-20^{\circ} \mathrm{C}$ for use in the competitive PCR.

RT-PCR for the M. tuberculosis mig (fadD19) gene homologue. RNA samples from intracellular and broth-grown $M$. tuberculosis were reverse transcribed in a $20 \mu \mathrm{l}$ reaction containing $0.5 \mu \mathrm{M}$ of downstream primer LCF4 (5'AGAGCAGATAGATGGCGT-3') from the mig gene homologue, $50 \mathrm{mM}$ Tris- $\mathrm{HCl}(\mathrm{pH} \mathrm{8.3)}, 75$ $\mathrm{mM} \mathrm{KCl}, 3 \mathrm{mM} \mathrm{MgCl}$ and $10 \mathrm{mM}$ DTT with 10 
$\mathrm{U}$ of Superscript RNase $\mathrm{H}^{-}$reverse transcriptase. A PCR was performed in a $50 \mu$ reaction containing equalised amounts of cDNA, 15\% glycerol, 0.125 $\mathrm{mM}$ of dNTPs, $10 \mathrm{mM}$ Tris- $\mathrm{HCl}$ (pH 8.3), $1.5 \mathrm{mM}$ $\mathrm{MgCl}_{2}, 50 \mathrm{mM} \mathrm{KCl}, 0.01 \%$ gelatin, $1 \mu \mathrm{M}$ of upstream primer LCF3 (5'CGCTACCTGTTCGACAAC-3'), $1 \mu \mathrm{M}$ of downstream primer LCF4 (5'AGAGCAGATAGATGGCGT-3'), and $0.5 \mathrm{U}$ of Taq I polymerase to amplify a fragment of $234 \mathrm{bp}$. The cycling parameters using the GeneAmp 9600 were $94^{\circ} \mathrm{C}-2 \mathrm{~min} ; 94-30 \mathrm{~s}, 50^{\circ} \mathrm{C}-30 \mathrm{~s} ; 72^{\circ} \mathrm{C}$ $30 \mathrm{~s}$ for 35 cycles and $72^{\circ} \mathrm{C}-10$ min for 1 cycle. The PCR products were analysed on 1\% agarose gel.

Limiting dilution PCR for the mig (fadD19) gene homologue. The cDNAs were diluted serially (1/320 to $1 / 2560)$ and a PCR was performed using the amplification conditions described above.

RT-PCR for the enoyl CoA hydratase (echA19) gene. RT-PCR was also performed for the gene that encodes enoyl CoA hydratase which overlaps the mig gene homologue on the complementary strand. RNA samples from intracellular and brothgrown $M$. tuberculosis RNA were reverse transcribed in a $20 \mu \mathrm{l}$ reaction containing $0.5 \mu \mathrm{M}$ of downstream primer ECHB (5'GTGGCAACCGTGGAAT-3') from echA19, 50 $\mathrm{mM}$ Tris- $\mathrm{HCl}$ (pH 8.3), $75 \mathrm{mM} \mathrm{KCl,} 3 \mathrm{mM} \mathrm{MgCl}_{2}$ and $10 \mathrm{mM}$ DTT with $10 \mathrm{U}$ of Superscript RNase $\mathrm{H}^{-}$reverse transcriptase. A PCR was performed in a $50 \mu \mathrm{l}$ reaction containing equalised amounts of cDNA, $15 \%$ glycerol, $0.125 \mathrm{mM}$ of dNTPs, 10 $\mathrm{mM}$ Tris-HCl (pH 8.3), $1.5 \mathrm{mM} \mathrm{MgCl}_{2}, 50 \mathrm{mM}$ $\mathrm{KCl}, 0.01 \%$ gelatin, $1 \mu \mathrm{M}$ of upstream primer ECHA (5'-AGCTGCCGTCCTTGAA-3'), $1 \mu \mathrm{M}$ downstream primer ECHB (5'GTGGCAACCGTGGAAT-3'), and $0.5 \mathrm{U}$ of Taq I polymerase to amplify a fragment of $260 \mathrm{bp}$. The cycling parameters using the GeneAmp 9600 were $94^{\circ} \mathrm{C}-5 \mathrm{~min} ; 94-30 \mathrm{~s}, 50^{\circ} \mathrm{C}-30 \mathrm{~s} ; 72^{\circ} \mathrm{C}-30 \mathrm{~s}$ for 35 cycles and $72^{\circ} \mathrm{C}-10 \mathrm{~min}$ for 1 cycle. The PCR products were analysed on a $1 \%$ agarose gel.
Competitive RT-PCR for echA19. A competitive template was designed using primers ECHC (5'AGCTGCCGTCCTTGAAGGTGAGGATGCAG C-3') and ECHB (5'-GTGGCAACCGTGGAAT3') to amplify a fragment of $190 \mathrm{bp}$. Fixed amounts of equalised cDNA were added to PCR mixes containing two fold dilutions of the competitive template (i.e. $3.12 \times 10^{6} \eta \mathrm{g}$ to $3.9 \times$ $10^{8}$ ๆg), $15 \%$ glycerol, $0.125 \mathrm{mM}$ of dNTPs, 10 $\mathrm{mM}$ Tris-HCl (pH 8.3), $1.5 \mathrm{mM} \mathrm{MgCl}_{2}, 50 \mathrm{mM}$ $\mathrm{KCl}, \quad 0.01 \%$ gelatin, and $0.5 \mathrm{U}$ of $\mathrm{Taq} \mathrm{I}$ polymerase, $1 \quad \mu \mathrm{M} \quad$ ECHA AGCTGCCGTCCTTGAA-3'), and $1 \mu \mathrm{M}$ ECHB to amplify the 260 bp native and $190 \mathrm{bp}$ competitive amplicons, respectively. The cycling parameters using the GeneAmp 9600 were $94^{\circ} \mathrm{C}$ $5 \mathrm{~min} ; 94-30 \mathrm{~s}, 50^{\circ} \mathrm{C}-30 \mathrm{~s} ; 72^{\circ} \mathrm{C}-30 \mathrm{~s}$ for 32 cycles and $72^{\circ} \mathrm{C}-10 \mathrm{~min}$ for 1 cycle. The PCR products were analysed on a $2 \%$ agarose gel.

\section{RESULTS}

A homologue of the M. avium mig gene was found in both the Sanger Centre and TIGR $M$. tuberculosis genome databases, indicating that this gene is present in both $\mathrm{H} 37 \mathrm{Rv}$ and in a clinical strain of $M$. tuberculosis. The $M$. tuberculosis homologue was $39.6 \%$ identical to the $M$. avium Mig $30 \mathrm{kDa}$ secreted protein and 46\% identical to the putative $34 \mathrm{kDa}$ protein - adjacent gene at the amino acid level (Fig.1a \& 1b). The $M$. tuberculosis gene encodes a protein of 540 amino acids $(\sim 59.7 \mathrm{kDa})$ in one open reading frame which is in sharp contrast to the two open reading frames in $M$. avium counterpart. A putative leader sequence with $9 \mathrm{~N}$-myristoylation sites spanning the whole length of the protein were identified suggesting that this is a membrane bound protein, a feature shared by the $30 \mathrm{kDa}$ secreted protein and $34 \mathrm{kDa}$ protein of M. avium. A putative AMP binding domain (LLYTGGTTGFPK) was identified at the 172nd amino acid residue of the protein with the putative tyrosine kinase phosphorylation site preceding the AMP domain, which was also present in Mig protein of $M$. avium. In addition, homologue of Mig protein in M. tuberculosis had aminoacyl-transfer RNA synthetases class-I signature (PADDVHAGHV) 
which appeared not to be present in any of the two proteins of $M$. avium counterpart.

The results of the competitive RT-PCR for $16 \mathrm{~S}$ gene (Fig. 2a and $\mathrm{b}$ ) were used to adjust the cDNA used for the cDNA from the intracellular bacilli and broth grown culture. RT-PCR showed that there was expression of the M. tuberculosis mig homologue by both intracellular and extracellular broth-grown bacilli (Fig. 3a), suggesting that this gene is not specifically expressed during intracellular infection of macrophages unlike the $M$. avium's mig gene. The expression of mig gene in broth grown culture could not be as a result of the $\mathrm{pH}$ of the media because the $\mathrm{pH}$ of the medium before inoculation of mycobacteria was found to be 6.8. However, the result did suggest that there might be upregulation of the gene in the intracellular bacilli.

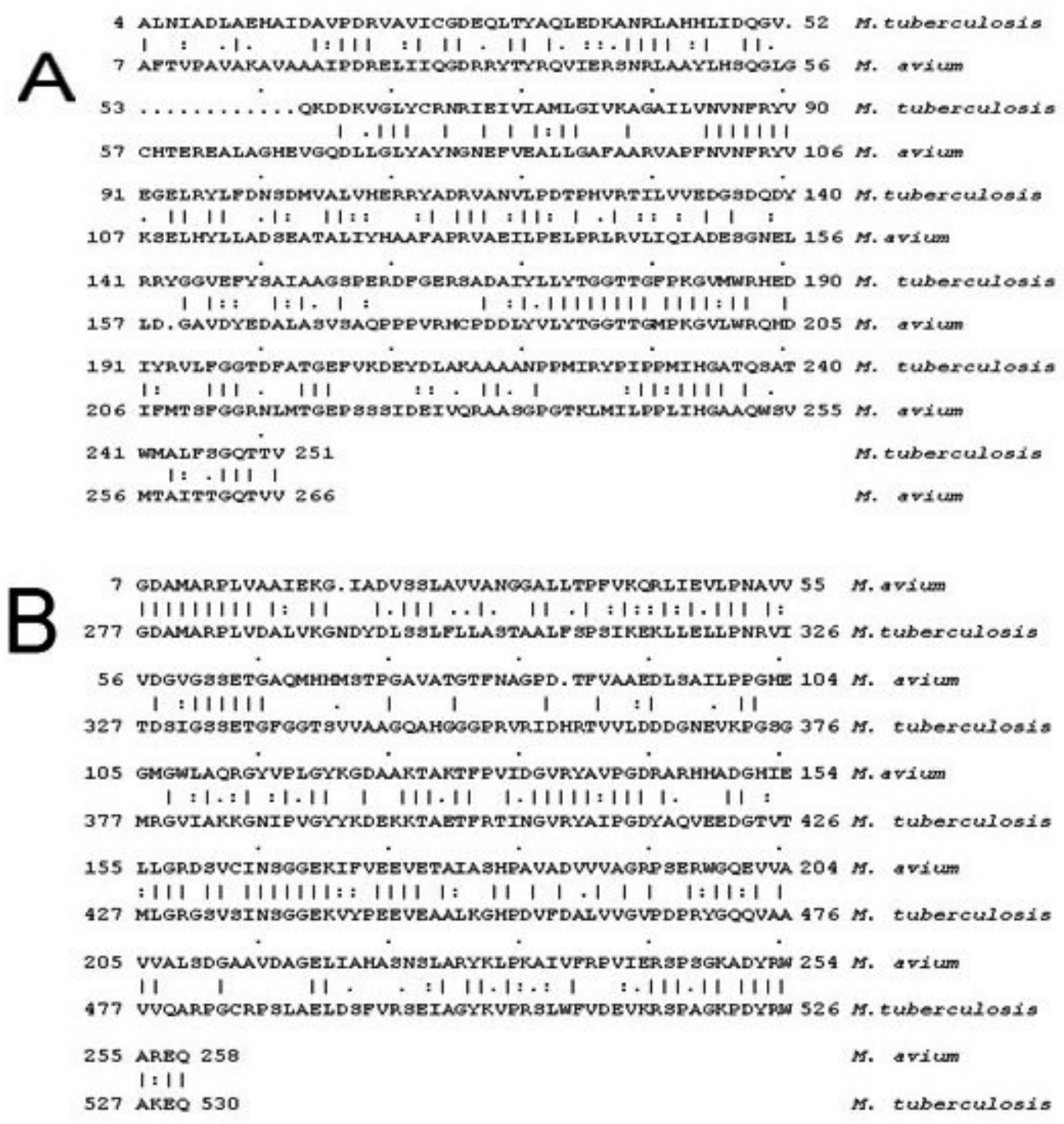

FIG 1 (a). Bestfit of the M. tuberculosis mig gene homolog and the M. avium mig gene encoding a $30 \mathrm{kDa}$ secreted protein. The box depicts the putative AMP binding domain. (b) Bestfit of the M. tuberculosis mig gene homologue and the M. avium mig gene encoding a putative $34 \mathrm{kDa}$ protein. 

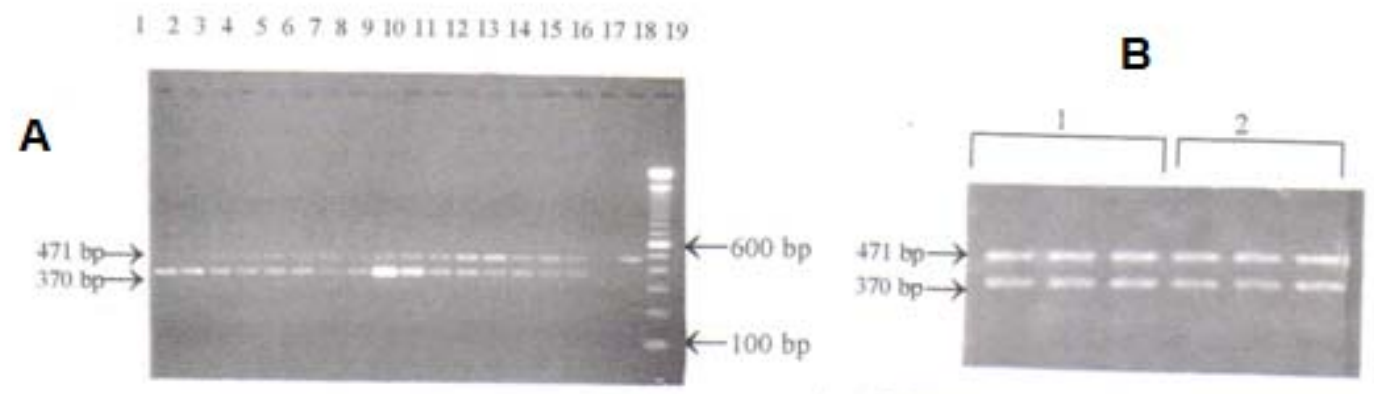

FIG. 2 (a) Competitive RT-PCR for 16S cDNA. Various amounts of 16S rRNA competitive DNA (0.05 pg to $0.0125 \mathrm{pg}$ ) competed against a fixed concentration of $16 \mathrm{~S}$ rRNA cDNA from M. tuberculosis. Lanes $1-8$ : intracellular bacilli (in duplicates); lanes 9-16: extracellular broth-grown bacilli (in duplicates); lanes 17 and 18: PCR negative and positive controls, respectively. Lane 19: 100 bp DNA ladder. The 471 bp and 370 bp products are the native and competitive amplicons, respectively. (b) Competitive PCR for 16s cDNA to confirm equal proportion of cDNA concentration. Amplicon of $16 \mathrm{~S}$ cDNA of intracellular bacilli at 1/10,000 dilution in triplicates; and lane 2: amplicon of 16S cDNA of extracellular bacilli at 1/20,000 dilution in triplicate. The $471 \mathrm{bp}$ and $370 \mathrm{bp}$ are native and competitive amplicons, respectively.

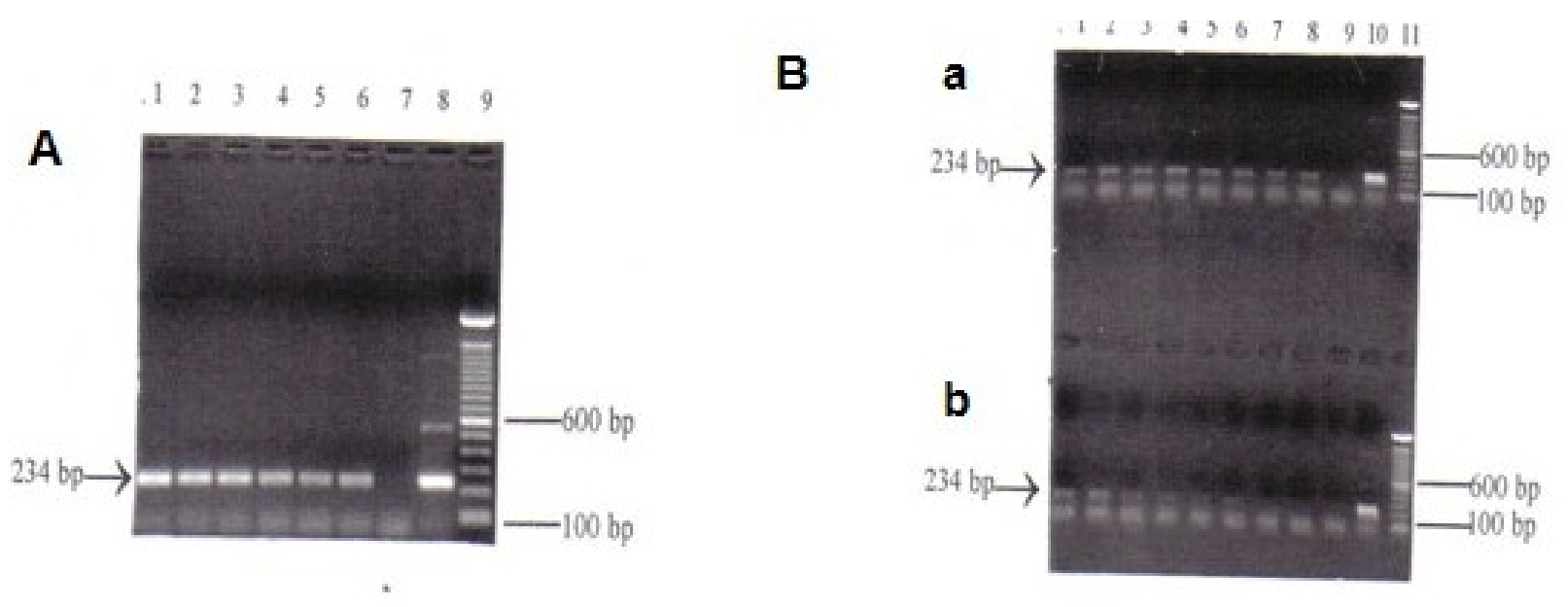

FIG. 3 (a) Expression of $M$. tuberculosis mig (fadD19) gene. Electrophoretic analysis of the RT-PCR products of mig gene of $M$. tuberculosis. Lanes 1, 2, and 3: PCR products from 1/5, 1/20, and 1/80 dilutions of the cDNA from intracellular bacilli, respectively. Lanes 4, 5, and 6: PCR products from 1/5, 1/20, and 1/80 dilutions of the cDNA from extracellular broth-grown M. tuberculosis, respectively. Lane 7: negative PCR control; lane 8: positive PCR control and lane 9: 100 bp DNA ladder. The arrow indicates the 234 bp mig (fadD19) product. (b) Quantification of mig (fadD19) expression in intracellular and broth-grown $M$. tuberculosis by limiting dilution RT-PCR. Electrophoretic analysis of the RT-PCR products of mig (fadD19) of M. tuberculosis. Lanes 1a and 2a: 1/320 dilution of the intracellular bacilli cDNA, lanes 3a and 4a: 1/640 dilution of intracellular bacilli cDNA; lanes 5a and 6a: 1/1280 dilution of intracellular bacilli cDNA; lanes 7a and 8a: 1/2560 dilution of intracellular bacilli cDNA; Lanes $1 \mathrm{~b}$ and $2 \mathrm{~b}$ : 1/320 dilution of the broth-grown bacilli cDNA, lanes $3 \mathrm{~b}$ and $4 \mathrm{~b}$ : 1/640 dilution of broth-grown bacilli cDNA; lanes 5b and 6b: 1/1280 dilution of broth-grown bacilli cDNA; lanes 7a and 8a: 1/2560 dilution of broth-grown bacilli cDNA; lanes 9a and 9b: negative PCR control; lanes 10a and 10b: positive PCR control; and lanes 11a and 11b: 100 bp DNA ladders. The arrows indicate the 234 bp mig (fadD19) product 

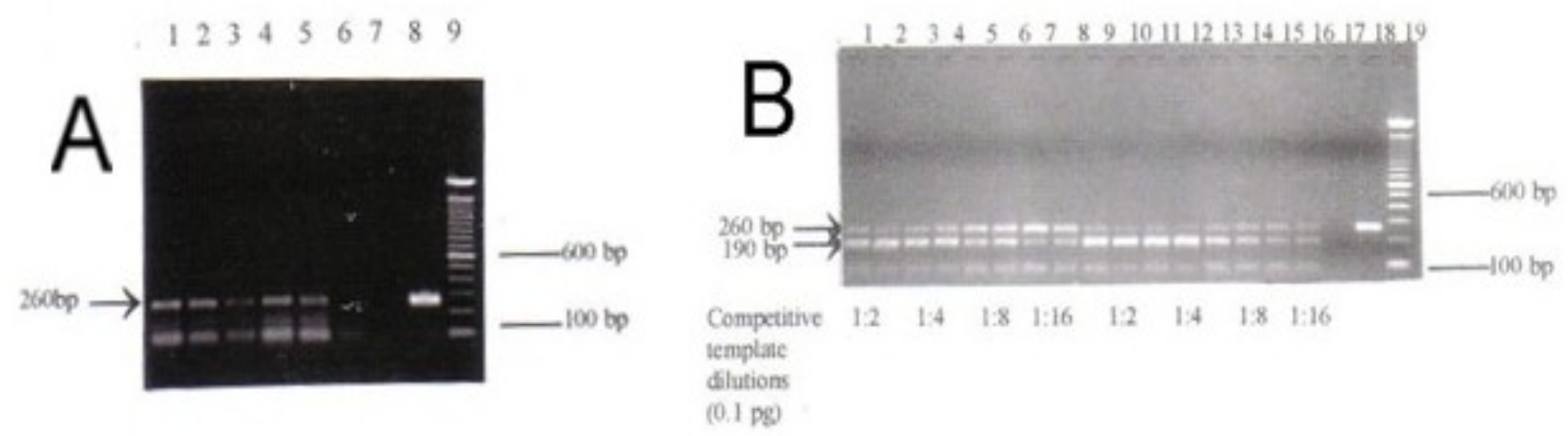

FIG. 4 (a) Expression of M. tuberculosis echA19 gene. Electrophoretic analysis of the RT-PCR products of echA19 gene of $M$. tuberculosis. Lanes 1, 2, and 3: PCR products from 1/5, 1/10, and 1/20 dilutions of the cDNA from intracellular bacilli, respectively. Lanes 4, 5, and 6: PCR products from 1/5, 1/10, and 1/20 dilutions of the cDNA from extracellular broth-grown M. tuberculosis, respectively. Lane 7: negative PCR control; lane 8: positive PCR control and lane 9: 100 bp DNA ladder. The arrow indicates the 260 bp echA19 product. (b) Quantification of echA19 expression in intracellular and broth-grown $M$. tuberculosis by competitive RT-PCR. Electrophoretic analysis of the RT-PCR products of echA19 of M. tuberculosis. Various amounts of echA19 competitive DNA (2-fold dilutions) competed against a fixed concentration of echA19 cDNA. Lanes 1-8: intracellular bacilli (in duplicates); lanes 9-16: extracellular broth-grown bacilli (in duplicates); lanes 17 and 18: PCR negative and positive controls, respectively; and lane 19: 100 bp DNA ladder. The 260 and 190 bp products are the native and competitive amplicons, respectively.

Unfortunately, a competitive RT-PCR could not be successfully developed due to competition between the native and competitive amplicons, which could not be overcome despite extensive changes to the thermal cycling parameters. However, a limiting dilution PCR was performed and this showed that there was 2-fold upregulation of the mig gene (fadD19) in intracellular bacilli over the broth-grown bacilli, as determined by the lack of the mig amplicon in the 1/2560 dilution of the cDNA in the broth-grown bacilli (Fig. 3b).

It was decided to also investigate the expression of the gene adjacent (echA19) to the mig homologue which was present on the opposite coding strand. This gene (echA19) encodes an enoyl CoA hydratase - a gene involved in fatty acid metabolism. RT-PCR showed that this gene was also expressed by both intracellular and brothgrown bacilli (FIG. 4a) but the presence and absence of the 260 bp amplicon in the third dilution from the intracellular and broth-grown bacilli, respectively showed that this gene was most likely to be upregulated during intracellular infection. Competitive PCR confirmed that there was a 2-fold upregulation of echA19 expression after $15 \mathrm{hr}$ of intracellular infection (Fig. 4b).

\section{DISCUSSION}

The mig gene of $M$. avium has been shown to be specifically expressed during infection of macrophages (Plum and Clarke-Curtiss, 1994, Plum et al., 1997), and the study looked at whether a similar gene could be present in M. tuberculosis. This study has taken the advantage of the availability of complete DNA sequences for the genome of $M$. tuberculosis to look for the presence of the gene in this bacterium. The mig (fadD19) gene has been found in $M$. tuberculosis and has been shown to be expressed constitutively and upregulated during intracellular infection. This would be in line with previous study carried out using microarray technology to dissect the intracellular environment of $M$. tuberculosis where they found upregulation of fadD19 and echA19 genes (Schnappinger et al., 2003). The function of this Mig protein was very difficult to predict since there was no convincing homology to any gene on the database. However, it had homology to the long chain fatty acid coA ligase of bacteria (24.6\% over 528 amino acid residues of Escherichia coli's 
long chain fatty acid coA ligase and 29\% identity over 543 amino acid residues of Archaeglobulus fulgidus's long chain fatty acid coA ligase) and also the enterobactin synthetase component $\mathrm{E}$ of Escherichia coli (25.4\% identity over 525 amino acid residues). Someone could speculate at this stage that the Mig protein homolog of M. avium in M. tuberculosis might have some dual functions. The evidence for this comes from the fact that there are two open reading frames for this protein in $M$. avium, with individual protein has homology to two proteins in the gene database. One thing that was clear from the result of the computer analysis was that the product of the gene might have some roles to play in metabolism.

One common feature that $M$. avium and $M$. tuberculosis have during intracellular infection of macrophages is that there is no acidification of the phagosome as a result of the exclusion of the proton ATPase pump (Clemens and Horwitz, 1996, Sturgill-Koszycki et al., 1996) which means is unlikely that the changes in $\mathrm{pH}$ would be the factor that regulates the expression in $M$. tuberculosis. The fact that this gene is constitutively expressed in broth cultures that is not acidic and upregulated during intracellular infection support this fact. There are many factors that mycobacteria could sense during intracellular infection, one of which might be the production of toxic fatty acids by macrophages in response to the presence of mycobacteria and mycobacteria do upregulates the expression of this gene in order to counteract the effect as a result of the production of vast amount of fatty acid coA ligase which are membrane bound. The toxic fatty acids are hydrophobic with hydrophilic tail makes it possible to penetrate the cell wall of mycobacteria, having this protein embedded in the cell membrane makes it very effective in detoxification by degrading this molecule with subsequent production of short chain fatty acid that could be incorporated into phospholipid. Fatty acid coA ligase has been implicated in some bacteria to have some roles to play in the evasion process of macrophages (Mahan et al., 1995, Sorrell et al., 1992). A homologue of this gene in Xanthomonnas campestris (a plant pathogen) uses the product of this gene in producing a substance called diffusible extracellular factor (DSF) which plays important role in controlling the expression of other proteins involve in the pathogenicity of the organism (Barber et al., 1997). Is it possible that $M$. tuberculosis or M. avium using the same process? Could this protein be involved in signal transduction because of the presence of tyrosine kinase phosphorylation site as a result of intracellular infection? Further work on these areas will probably throw some light in unravelling the process. The field of molecular pathogenesis has changed over the last few years with the release of complete genome sequencing data of some bacteria including $M$. tuberculosis (Cole et al., 1998). The completed genome sequences reveal the abundance of genes (genes coding for 36 acylCoA synthases and related enzymes, 21 enoyl CoA hydratases, and 36 fadD genes) encoding components of fatty acid oxidation systems (Cole et al., 1998), suggesting the importance of fatty acid metabolism to $M$. tuberculosis. There is vast knowledge of information the scientific community could gain from the use of these database as demonstrated by this study. It also shows that the pathogenic mycobacteria might have evolved from a common ancestor with divergence over a period of time which could account for the differences in the organisation of the mig gene along with control of expression of this gene.

\section{Acknowledgements}

The authors acknowledge Prof. P. Butcher, Dr A.F. Cunningham and Prof A.M. Geddes, for their cooperation during the course of this work. This work is funded by Glaxo Smithkline, United Kingdom as part of action TB initiative.

\section{REFERENCES}

Altschul, S. F., Gish, W., W.Miller, Myers, E. W. and Lipman, D. J. (1990) Basic local alignment search tool. Journal of Molecular Biology, 215, 403-410.

Barber, C. E., Tang, J. L., Feng, J. X., Pan, M. Q., Wilson, T. J., Slater, H., Dow, J. M., Williams, P. and J.Daniels, M. (1997) A novel regulatory system required for pathogenicity of 
Xanthomonas campestris is mediated by a small diffusible signal molecule. Microbiology, 24, 555566.

Celi, F. S., Zenilman, M. E. and Shuldiner, A. R. (1993) A rapid and versatile method to synthesize internal standards for competitive PCR. Nucleic Acids Research, 21, 1047.

Clemens, D. L. and Horwitz, M. A. (1996) The Mycobacterium tuberculosis phagosome interacts with early endosomes and is accessible to exogenously administered transferrin. J Exp Med, 184, 1349-55.

Cole, S. T., Brosch, R., Parkhill, J., et al (1998) Deciphering the biology of Mycobacterium tuberculosis from the complete genome sequence. Nature, 393, 537-44.

Corbett, L. and Raviglione, M. (2005) Global Burden of Tuberculosis: Past, Present, and Future. In Tuberculosis and the Tubercle Bacillus(Eds, Cole, S. T., Eisenach, K. D., McMurray, D. N. and Jr., W. R. J.) ASM, Washington DC, pp. 3-12.

Kempsell, K. E., Ji, Y. E., Estrada, I. C., Colston, M. J. and Cox, R. A. (1992) The nucleotide sequence of the promoter, 16S rRNA and spacer region of the ribosomal RNA operon of Mycobacterium tuberculosis and comparison with Mycobacterium leprae precursor rRNA. J Gen Microbiol, 138 Pt 8, 1717-27.

Mahan, M. J., Tobias, J. W., Slauch, J. M., Hanna, P. C. and Collier, R. J. (1995) Antibiotic-based selection for bacterial genes that are specifically induced during infection of a host. Proceedings of the National Academy of Sciences of the United States of America, 92, 669-673.

Mangan, J. A., Sole, K. M., Mitchison, D. A. and Butcher, P. D. (1997) An effective method of RNA extraction from bacteria refractory to disruption, including mycobacteria. Nucleic Acids Research, 25, 675-676.

Plum, G., Brenden, M., Clark-Curtiss, J. E. and Pulverer, G. (1997) Cloning, sequencing, and expression of the mig gene of Mycobacterium avium, which codes for a secreted macrophageinduced protein. Infection and Immunity, 65, 45484557.

Plum, G. and Clarke-Curtiss (1994) Induction of Mycobacterium avium gene expression following phagocytosis by human macrophages. Infection and Immunity., 62, 476-483.

Schlesinger, L. S., Bellinger-Kawahara, C. G., Payne, N. R. and Horwitz, M. A. (1990) Phagocytosis of Mycobacterium tuberculosis is mediated by human monocyte complement receptors and complement component C3. Journal of Immunology, 144, 2771-2780.

Schnappinger, D., Ehrt, S., Voskuil, M. I., Liu, Y., Mangan, J. A., Monahan, I. M., Dolganov, G., Efron, B., Butcher, P. D., Nathan, C. and Schoolnik, G. K. (2003) Transcriptional Adaptation of Mycobacterium tuberculosis within Macrophages: Insights into the Phagosomal Environment. J Exp Med, 198, 693-704.

Sorrell, T. C., Muller, M. and Sztelma, K. (1992) Bacterial metabolism of human polymorphonuclear leukocyte-derived arachidonic acid. Infection and Immunity, 60, 1779-1785..

Sturgill-Koszycki, S., Schaibe, U. E. and Russell, D. G. (1996) Mycobacterium containing phagosomes are accessible to early endosomes and reflect a transitional state in normal phagosome biogenesis. EMBO Journal, 15, 6960-6968.

WHO (2007). Global Tuberculosis Control Surveillance, Planning, Financing. 